\title{
Sensitivity Improvement of an Impedimetric Immunosensor Using Functionalized Iron Oxide Nanoparticles
}

\author{
Imen Hafaid,, ${ }^{1,2}$ Asma Gallouz, ${ }^{1}$ Walid Mohamed Hassen, ${ }^{1}$ Adnane Abdelghani, ${ }^{3}$ Zina Sassi, ${ }^{2}$ \\ Francois Bessueille, ${ }^{1}$ and Nicole Jaffrezic-Renault ${ }^{1}$ \\ ${ }^{1}$ Laboratoire des Sciences Analytiques (UMR CNRS 5180), Université de Lyon, Batiment Raulin, Université de Claude Bernard, \\ 43 boulevard du 11 Novembre 1918, 69622 Villeurbanne Cedex, France \\ ${ }^{2}$ Laboratoire AMPERE (UMR CNRS 5180), INSA de Lyon, 69621 Villeurbanne, France \\ ${ }^{3}$ Unité de Recherche de Physique des Semiconducteurs et Capteurs, IPEST, La Marsa 2070, Tunisia \\ Correspondence should be addressed to Imen Hafaid, imen_haf@yahoo.fr
}

Received 30 December 2008; Revised 18 May 2009; Accepted 8 July 2009

Recommended by Wojtek Wlodarski

\begin{abstract}
This work has explored the development of impedimetric immunosensors based on magnetic iron nanoparticles (IrNP) functionalized with streptavidin to which a biotinylated FAB part of the antibody has been bound using a biotin-streptavidin interaction. SPR analysis shows a deviation on the measured (angle) during antigen-antibody recognition whereas label free detection using by EIS allows us to monitor variation of polarization resistance. Before detection, layers were analyzed by FTIR and AFM. Compared to immobilization of antibody on bare gold surface using aminodecanethiol SAM, antibody immobilization on nanoparticles permitted to reach lower detection limit: $500 \mathrm{pg} / \mathrm{ml}$ instead of $1 \mathrm{ng} / \mathrm{ml}$ to in the case of EIS and $300 \mathrm{ng} / \mathrm{ml} \mathrm{instead}$ of $4.5 \mu \mathrm{g} / \mathrm{ml}$ in the case of SPR. Thus, it permitted to improve the sensitivity: from $257.3 \Omega \cdot \mathrm{cm}^{2} \cdot \mu \mathrm{g}^{-1} \cdot \mathrm{ml}$ to $1871 \Omega \cdot \mathrm{cm}^{2} \cdot \mu \mathrm{g}^{-1} \cdot \mathrm{ml}$ in the case of EIS and from $0.003^{\circ} \mu \mathrm{g}^{-1} \cdot \mathrm{ml}$ to $0.094^{\circ} \mu \mathrm{g}^{-1} \cdot \mathrm{ml}$ in the case of SPR.
\end{abstract}

Copyright ( 2009 Imen Hafaid et al. This is an open access article distributed under the Creative Commons Attribution License, which permits unrestricted use, distribution, and reproduction in any medium, provided the original work is properly cited.

\section{Introduction}

Immunosensors have arisen great interest with expectation of providing fast and highly sensitive immunological response. Immunosensors have widespread applications in clinical diagnostics, food safety and quality control, biological analysis, and environmental monitoring [1-5]. During the past years, the research in this field evolved quickly with the aim of improving the performance of the biosensors (specificity, stability, sensitivity, detection limit, etc.). In this approach, recent studies have been focused on the use of nanoparticles as tools to amplify the response signal from antibody-antigen interaction, which led to the improvement of the characteristics of the biosensor [6-8].

In the recent years, nanomaterials have been widely used in bioanalytical chemistry, bioseparations, and bioimaging for their unique and particular properties [9-12]. Iron oxide nanoparticles or magnetic beads are a kind of nanomaterial which might play an important role in the construction of electrochemical biosensors [13]. Firstly, iron oxide nanoparticles have a very large surface area and good bio-compatibility. Most practically, they can be magnetic ally immobilized on Au substrates [14, 15]. Furthermore, these magnetic particles are especially designed for concentration, separation, purification, and identification of molecules and specific cells [16-18]. Besides, they are particularly suitable for integration in microfluidic devices.

A new approach allows to attach these magnetic particles by covalent binding on the substrate previously functionalized with self-assembled monolayer (SAM). The tailoring of the physical chemistry of surfaces has led to an increasing interest in using SAMs of thiolor sulfur compounds as insulator [19-22]. The formed single molecular organized structures have numerous advantages, such as insulating nanostructures, free of defects, much more stable, especially in water and other solvents [23].

In this work, we report the development of an electrochemical Immunosensor based on iron oxide nanoparticles functionalized with the streptavidine. The Biotine tag antiD-dimer reduced antibody was immobilized on the surface 
of iron oxide nanoparticles linked to a previously functionalized gold electrode using 11-Amino-1-undecanethiol and glutaraldehyde as coupling agent.

For the purpose of developing this Immunosensors, surface plasmon resonance (SPR) and electrochemical impedance spectroscopy (EIS) techniques were selected. In first time, surface plasmon resonance (SPR) was used as optical characterization technique [24]. This technology has emerged as a powerful tool for in situ control of biomolecular interaction in real time [25]. SPR sensors are based on surface plasmon or electromagnetic wave propagating along a metal/dielectric interface. Since the wave vector of plasmon, $\mathrm{ksp}$, depends on the dielectric constants of both media, $\mathrm{ksp}=$ $k_{0} \sqrt{\varepsilon_{\text {metal }} \varepsilon_{\text {sample }} /\left(\varepsilon_{\text {metal }}+\varepsilon_{\text {sample }}\right)}$ (where $k_{0}$ is the free space wave vector of the optical wave), it is extremely sensitive to properties of the dielectric medium which is in contact with the metal.

Surface plasmons are generally excited in the Kretchmann configuration by directing p-polarized light to a glass prism and reflecting from a gold film [26]. When the tangential $x$-component of the incident optical wave vector, $k x$, is matched with ksp, the pumping light energy is transferred to surface plasmons:

$$
k x=k_{0} \cdot n_{\text {glass }} \cdot \sin \theta_{\text {inc }}=\mathrm{ksp}
$$

where $n_{\text {glass }}$ is the refractive index of the prism and $\theta_{\text {inc }}$ is the angle of incidence.

Therefore, the information of biological binding (recognition) events on the gold film can be obtained by carefully monitoring the SPR coupling characteristics. In most SPR systems, the information of the biomolecular interactions is obtained from measurements of the angular or the spectral characteristics of light reflected under SPR.

In second time, electrochemical impedance spectroscopy (EIS) was used as transduction technique for the label free detection. This technique is an effective tool used on the one hand, for the qualitative and quantitative characterization of electrochemical processes occurring in the conducting polymer films $[27,28]$. On the other hand, to probe the interfacial properties of modified electrode and often used for understanding chemical transformations and processes associated with the conductive supports and it can be used to probe antibody-antigen interaction in order to study the immunosensor responses [29-31].

While comparing with the development of an immunosensor-based on antibody coupled on a SAM, we attempt to show that the use of iron oxide nanoparticles allows to amplify the response signal and leads to the improvement of immunosensor characteristics.

\section{Materials and Methods}

2.1. Reagent. The magnetic coated streptavidin nanoparticles that display a diameter of $200 \mathrm{~nm}$ and an iron oxide content of about 70\% (cf. Figure 1) were purchased from Ademtech SA. 11-Amino-1-undecanethiol (AUT) and Glutaraldehyde (GA) were obtained from Aldrich. Neutravidin

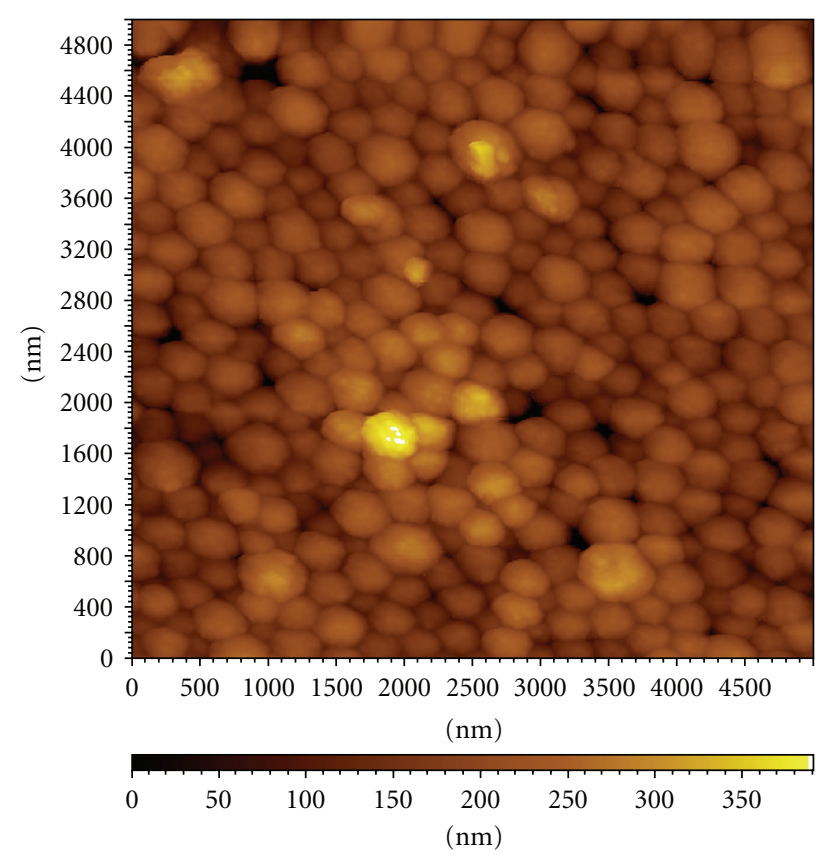

FIgURE 1: AFM images of the iron oxide nanoparticles.

(Neutv) was purchased from Pierce. The biot-tag anti-Ddimer reduced antibody (Fab fragment Biot-ScAc) and the antigen (peptide conjugated to BSA) were obtained from Wyeth Company (Aberdeen UK).

The buffer solution used for the electrochemical impedance experiments was Phosphate Buffer Saline (PBS) containing $137 \mathrm{mM} \mathrm{NaCl}, 2.7 \mathrm{mM} \mathrm{KCl}, 0.01 \mathrm{M} \mathrm{K}_{2} \mathrm{HPO}_{4}$ and $0.01 \mathrm{M} \mathrm{KH} \mathrm{KH}_{4}, \mathrm{pH}$ 7. For the cyclic voltammetry experiments, the redox couple $\mathrm{Fe}(\mathrm{CN})_{6}^{3-} / \mathrm{Fe}(\mathrm{CN})_{6}^{4-}$ at a $5 \mathrm{mM}$ concentration was used. All solutions were made up in ultrapure water (resistance $18.2 \mathrm{M} \Omega \mathrm{cm}^{-1}$ ) produced by a Millipore Milli-Q system.

\subsection{Instrumentation}

2.2.1. Surface Plasmon Resonance (SPR) Technique and GoldCoated Substrates. Surface plasmon resonance spectrometer "Biosuplar 3" (http://www.micro-systems.de/) was developed at the Institute of Semiconductor Physics of the National Academy of Sciences of Ukraine (Kyiv). This optoelectronic device based on the phenomenon of surface plasmon resonance in the Kretchmann's optical configuration was controlled by a computer via self-developed software. Gold film (45 nm) deposited through Cr adhesion layer (1$1.5 \mathrm{~nm}$ ) onto a glass chip represented the sensor surface. An incident beam of p-polarized light from a semiconductor laser diode $(\lambda=650 \mathrm{~nm})$ excited an oscillation of electronic plasma (i.e., surface plasmon) in this metallic film. A special prism capable of rotation on a computer-defined angle provided optimal conditions for the plasmon excitation. A plasmon resonance itself was registered as a drastic decrease of reflected light intensity. 
In the present study, the SPR spectrometer flow cell ( $V \sim$ $20 \mu L$ ) was connected to a Gilson Minipuls 3 pump.

2.2.2. Impedance Spectroscopy. Cyclic Voltammetry and Electrochemical Impedance Spectroscopy (EIS) measurements were performed using a Voltalab 80 impedance analyzer. A conventional three electrode cell was used, including a saturated calomel electrode (SCE) as reference electrode, a platinum wire as counter electrode $\left(0.54 \mathrm{~cm}^{2}\right)$, and a modified gold working electrode $\left(0.19 \mathrm{~cm}^{2}\right)$. The impedance spectroscopy measurements were carried out in the frequency range from $0.05 \mathrm{~Hz}$ to $100 \mathrm{KHz}$ at dc potential $-400 \mathrm{mV}$, using a modulation voltage of $10 \mathrm{mV}$. Data simulation was made with the commercial software Zview (Scribrerand associates, Charlottesville, VA). All electrochemical measurements were carried out at room temperature in PBS pH 7.4.

2.2.3. Atomic Force Microscopy . Atomic Force Microscopy (AFM) experiments were performed in air, using a Pico Plus molecular imaging microscope with a $300 \mathrm{~nm}$ scanning head. The images were registered in tapping mode using silicon pyramidal $\mathrm{Si}_{3} \mathrm{~N}_{4}$ tips. The overage resonance frequency of the tips was $300 \mathrm{kHz}$ in air. The image presented in this paper was acquired with 512 lines and were processed by means of a plane fit.

2.2.4. FTIR Spectroscopy. NICOLET 710 FT-IR spectrometer equipped with an MIR (Middle Infrared) source an MCT/A detector was used to obtain the FTIR spectra. All the spectra are collected during 128 scans for the reference and sample. Our strategy consisted of recording in reflexion mode the spectrum of the cleaned gold substrate and then of the gold substrate modified with the SAM. The spectrum of the cleaned electrode served as a reference. The difference between two spectra gave the spectrum of SAM.

2.2.5. Preparation of the Modified Electrode. Two systems were prepared, one based on the use of a thiol SAM (system 1) and the other based on the use of functionalized magnetic iron nanoparticles with the streptavidin (system 2).

In the first step of the electrode modification, the 11Amino-1-undecanethiol monolayer is chemisorbed on the gold electrode surface and exposed an array of amino groups towards the solution. In the second step, the electrode surface is activated with aldehyde groups and left the second carbonyl group of glutaraldehyde free on the top of the surface. Formation of bridge structures due to the reaction of both aldehyde groups of glutaraldehyde with the amino groups may be prevented by the application of a high concentration of the bifunctional reagent, that is, GA [32]. The last step, the amino group of neutravidin (Scheme 1(a): system 2) and of magnetic iron nanoparticles coated by streptavidin (Scheme 1(b): system 2 ) are covalently coupled with the aldehyde group of glutaraldehyde. The new membrane rich in binding sites of biotin allowed forming the high binding affinity with the biotin ligand attached on scAb antibody fragment. The Fab fragments were biotinylated in the hinge region, to ensure orientation of the fragment at the

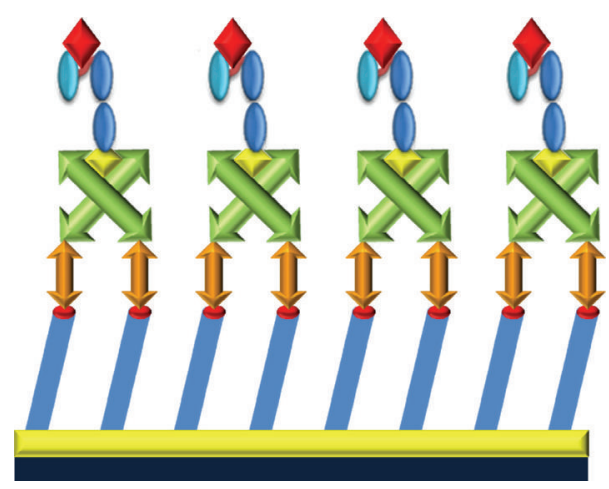

(a)

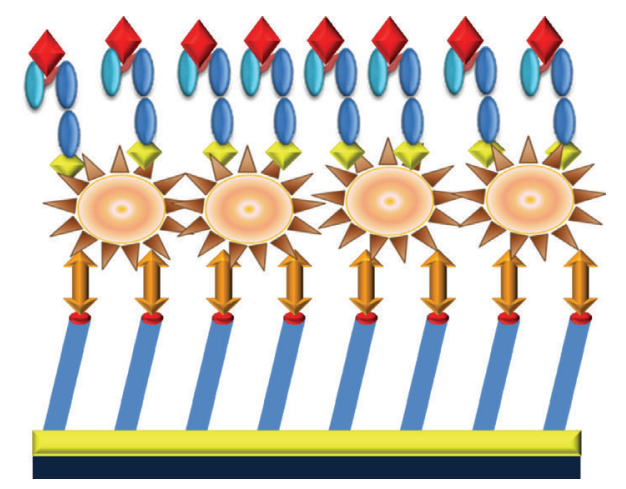

(b)
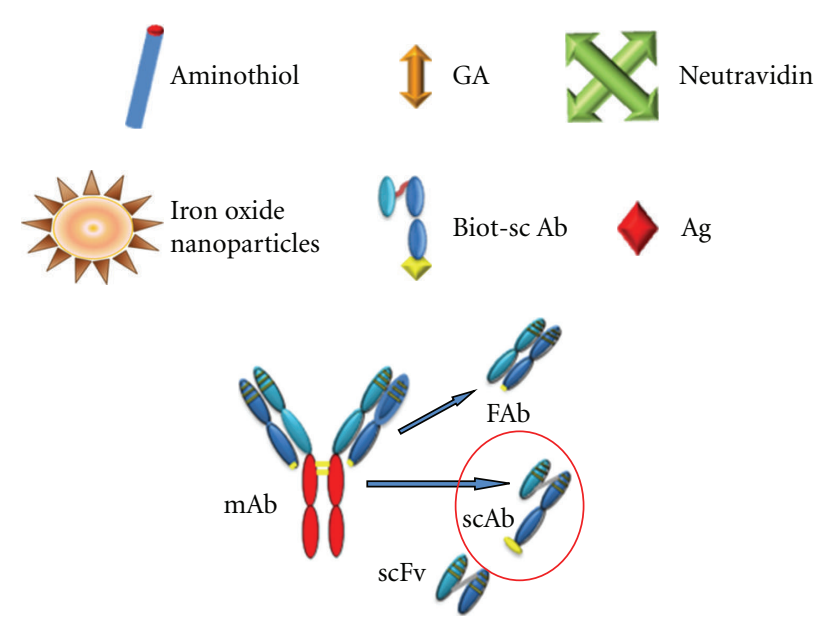

(c)

Scheme 1: (a) System 1: schematic representation of the fabrication process of the multilayer immunosensor based on SAM. (b) System 2: schematic representation of the fabrication process of the multilayer immunosensor based on iron oxide nanoparticles. (c) Fab fragment biotinylated antibody.

surface with the binding site facing a way from the surface. The system is shown schematically in Scheme 1(c).

Two types of gold electrodes are used as substrate for the biolayer fabrication. Evaporated gold ( $\sim 300 \mathrm{~nm}$ thickness) deposited on silicon using a titanium layer ( $30 \mathrm{~nm}$ thickness) used as substrate for the electrochemical experiments. These 


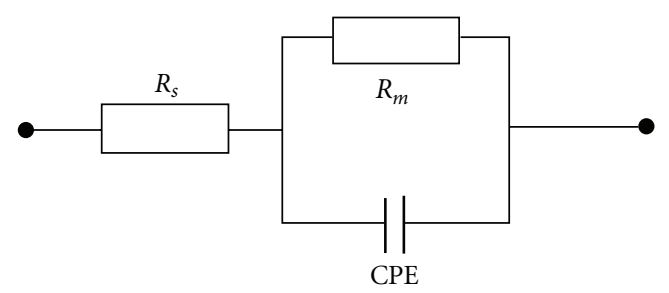

Scheme 2: Equivalent circuit model for complex impedance plot.

gold electrodes were provided by LAAS, CNRS Toulouse. Before modification, the gold surface was cleaned in an ultrasonic bath for 10 minutes in acetone, dried under a dry $\mathrm{N}_{2}$ flow and then dipped for 1 minute into "piranha solution" comprising $7: 3$ (v/v) $98 \% \mathrm{H}_{2} \mathrm{SO}_{4} / 30 \% \mathrm{H}_{2} \mathrm{O}_{2}$. The gold substrate was then rinsed 2 to 3 times with ultrapure water and dried under nitrogen flow. For the optical characterization the gold film ( $45 \mathrm{~nm}$ ) deposited through $\mathrm{Cr}$ adhesion layer $(1-1.5 \mathrm{~nm})$ onto a glass chip was used. The gold surface was cleaned in the same way than the other ones, with a "piranha solution," but for 15 seconds.

The aminothiol monolayer was prepared by soaking a clean gold electrode $(\mathrm{Au})$ in $0.1 \mathrm{mM} 11$-Amino1-undecanethiol (AUT) in ethanol solution for 24 hours at room temperature in darkness, washing the electrode thoroughly with ethanol to remove physically adsorbed 11Amino-1-undecanethiol, immersing the electrode in PBS ( $\mathrm{pH}$ 7.4) containing $5 \%(\mathrm{v} / \mathrm{v})$ glutaraldehyde (GA) solution for 1 hour 30 minutes, and rinsing with PBS. Afterwards, for system 1, the electrode was immersed into $10^{-5} \mathrm{mM}$ Neutravidin solution for 2 hours to achieve Schiff base reaction between the aldehyde group of glutaraldehyde and the amino group of Neutravidin. And for system 2, the electrode was immersed into $0.25 \mathrm{mg} / \mathrm{ml}$ magnetic coated streptavidin nanoparticles solution for 12 hours to form the Schiff base between the aldehyde group of glutaraldehyde and the amino group of streptavidin. Antibody scAb fragment with a Biotin tag $(0.4 \mathrm{mg} / \mathrm{ml})$ was immobilized on AUT/GA/Neut. films for 1 hour at room temperature, followed by thorough rinsing with PBS. Antigen at different concentrations was incubated on immobilized antibody for 30 minutes at room temperature. Scheme 1 shows the schematic steps for the formation of the biolayer and the antigen-antibody recognition for both systems.

\section{Results and Discussion}

3.1. Characterization of Self-Assembled Monolayer. The modified gold electrode with the self-assembled monolayer 11Amino-1-undecanethiol was followed by several technique of characterizations.

3.1.1. Cyclic Voltammetry. Cyclic voltammetry is an effective and convenient method for probing the feature of the modified electrode surface. The step of the SAMs deposition was controlled by this technique. As is shown in Figure 2(a), the cyclic voltammogram defines the characteristics of a

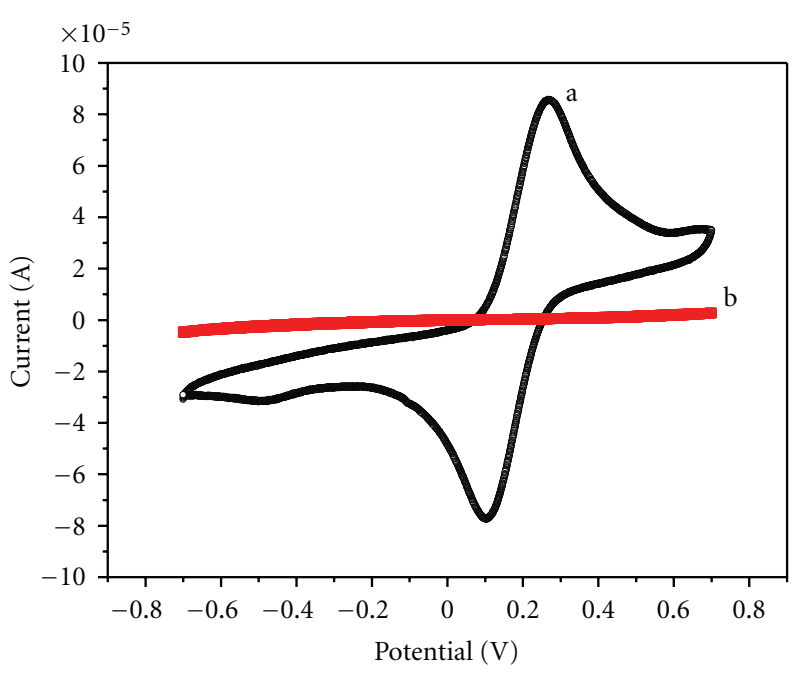

FIGURE 2: Cyclic voltammetric measurement with the presence of the $5 \mathrm{mM}$ redox-probe $3\left[\mathrm{Fe}(\mathrm{CN})_{6}\right] / \mathrm{K}_{4}\left[\mathrm{Fe}(\mathrm{CN})_{6}\right]$ : (a) bare gold electrode; (b) SAM/Au-electrode. All experiments were performed in PBS $10 \mathrm{mM} \mathrm{pH} \mathrm{7.4,} \mathrm{scan} \mathrm{rate} 50 \mathrm{mV} / \mathrm{s}$.

diffusion controlled redox process observed at the cleaned bare gold electrode. This reversible cyclic voltammogram indicates a clean gold surface. The formation of the SAM on the gold electrode (Figure 2(b)) resulted in an insulating surface in a sort of way and thus blocked the diffusion of ferro/ferricyanide towards the surface of electrode, therefore the blocking of the Faradaic current.

3.1.2. Impedance Measurement. Electrochemical Impedance Spectroscopy (EIS) is an effective tool for probing the feature surface-modified electrode while controlling its electrical properties [33,34]. In a first time, this technique was used for the characterization of the impedance behavior of SAM modified gold electrode and for subsequent extraction of useful information from this. In Figure 3 Nyquist impedance plots for Au-electrode and SAM modified electrode at $-400 \mathrm{mV}$ dc potentials are presented, where $\operatorname{Re}(z)$ is the real part and $\operatorname{Im}(z)$ is the imaginary part of the complex impedance $Z$ [35]. The membrane resistance values, $R_{m}$, were extracted from fitted data (Table 3) which are 8292 and $37120 \Omega \mathrm{cm}^{2}$ for bare Au-electrode and mixed modified Auelectrode, respectively. The values of the fractional coverage area of the SAM monolayer $(\theta)$ can be calculated from the impedance diagrams using [36]

$$
\theta=1-\frac{R_{m}}{R_{m}^{*}},
$$

where $R_{m}$ and $R_{m}^{*}$ are the values of the membrane resistance derived from the impedance diagram of the bare gold electrode and of the gold electrode SAM functionalized, respectively. In our system the coverage area was equal to $77 \%$.

3.1.3. SPR Measurement. Optical characterization of the SAM layer was performed by SPR technique. Figure 4 
TABLE 1: Optical parameters obtained by fitting the SPR curves for system 1 based on SAM.

\begin{tabular}{|c|c|c|c|c|c|}
\hline Layer & Thickness (nm) & $n$ & kapa & $\varepsilon^{\prime}$ & $\varepsilon^{\prime \prime}$ \\
\hline Bare gold & 50.72 & 0.17 & 3.988 & -15.87 & 1.355 \\
\hline Thiol & 2.16 & 1.34 & 0 & 1.791 & 0 \\
\hline GA & 0.1 & 1.45 & 0 & 2.10 & 0 \\
\hline Nev. & 0.8 & 1.45 & 0 & 2.10 & 0 \\
\hline $\mathrm{Ab}$ & 0.4 & 1.45 & 0 & 2.10 & 0 \\
\hline
\end{tabular}

TABLE 2: Optical parameters obtained by fitting the SPR curves for system 2 based on iron oxide nanoparticles.

\begin{tabular}{|c|c|c|c|c|c|}
\hline Layer & Thickness (nm) & $n$ & kapa & $\varepsilon^{\prime}$ & $\varepsilon^{\prime \prime}$ \\
\hline Bare gold & 50.72 & 0.17 & 3.89 & -15.87 & 1.355 \\
\hline Thiol & 2.16 & 1.34 & 0 & 1.791 & 0 \\
\hline GA & 0.1 & 1.45 & 0 & 2.10 & 0 \\
\hline Iron oxide nanoparticles & 301 & 0.28 & 2.98 & -8.802 & 1.6688 \\
\hline $\mathrm{Ab}$ & 1.2 & 1.45 & 0 & 2.10 & 0 \\
\hline
\end{tabular}

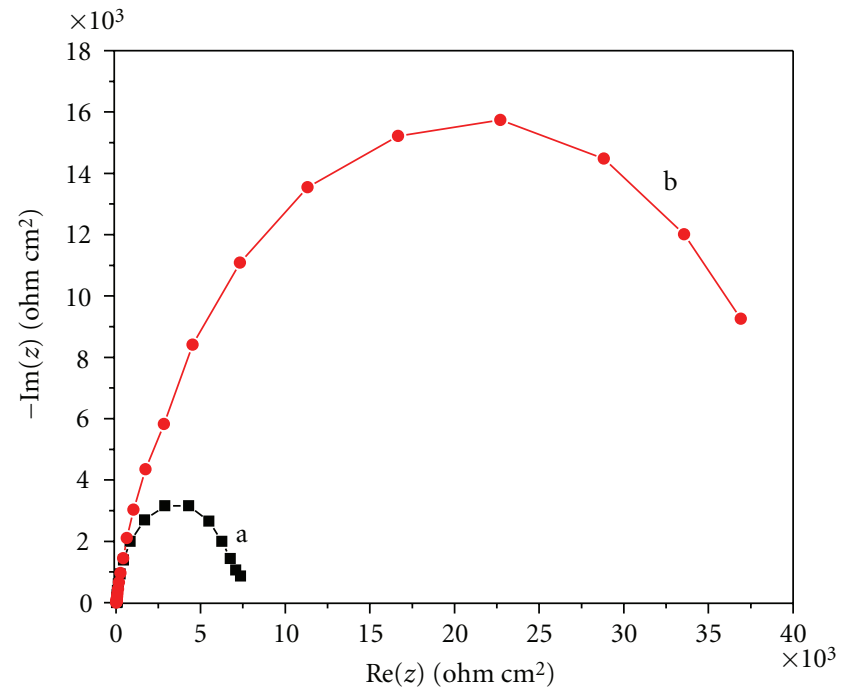

Figure 3: Nyquist diagram $(-\operatorname{Im}(z)$ versus $\operatorname{Re}(z))$ at $-400 \mathrm{mV}$ versus SCE in PBS solution $10 \mathrm{mM}$ pH 7.4, obtained for the nonFaradic impedance measurement corresponding to (a) bare gold electrode and (b) self-assembled monolayer functionalized gold electrode.

presents the spectra of the reflected intensity versus incidence angle. These spectra show an incidence angle shift of $0.563^{\circ}$ between the bare gold layer (Figure 4(a)) and the gold layer coated with SAM layer (Figure 4(b)). By fitting these spectra using the Winspall program, the thickness of each layer was calculated (see Table 1). The thickness of the gold around of $50.72 \mathrm{~nm}$ was checked by this fitting. Also, the thickness of the SAM layer was estimated to $2.16 \mathrm{~nm}$. Furthermore, this fitting allows estimating the dielectric constant $\varepsilon$. of each layer from [37]

$$
\varepsilon=\varepsilon^{\prime}+i \varepsilon^{\prime \prime},
$$

with $\varepsilon^{\prime}=n^{2}-\mathrm{kapa}^{2}$, and: $\varepsilon^{\prime \prime}=2 \cdot n \cdot$ kapa.

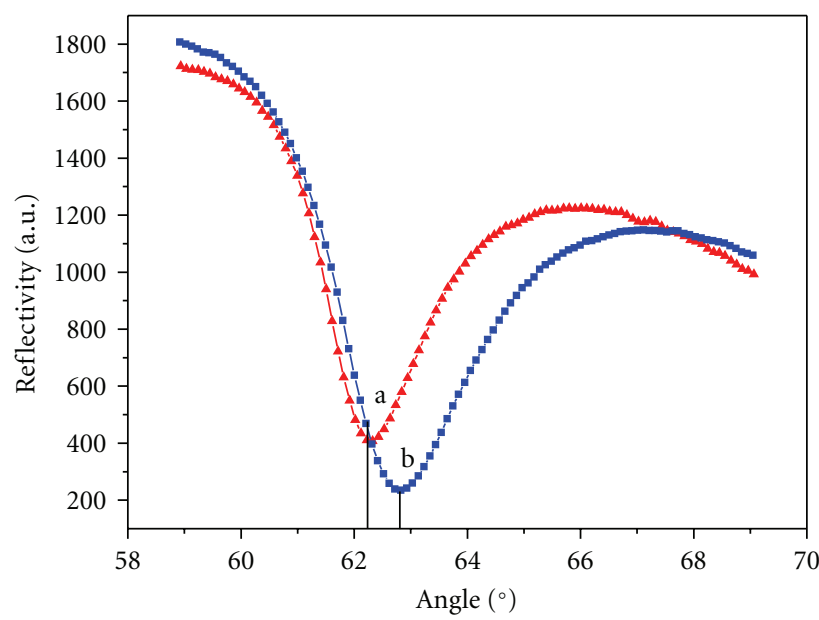

FIGURE 4: In situ SPR curves (reflected intensity $(R)$ versus incidence angle $(\theta)$ ) corresponding to: (a) bare gold electrode and (b) self-assembled monolayer functionalized gold electrode.

As kapa is the adsorbents index and $n$ is the refraction index that were determined by fitting. Then the dielectric constant of the gold film was estimated to $\varepsilon=-15.87+$ $i 1.355$. These values correspond to the wavelength of $\lambda=$ $650 \mathrm{~nm}$ and they are comparable with literature [38].

\subsection{Optical and Electrical Characterization of the Biofilm of System 1 (Based on SAM) and the Biofilm of System 2 (Based on Iron Oxide Nanoparticles)}

3.2.1. SPR Measurement. A typical kinetics of step-by-step formation of the biofilm (system 1) is shown in Figure 5, that present the SPR angle sensorgrams. As the first step, we injected a glutaraldehyde solution (5\%) into the sensor head containing a gold sensor surface functionalized by aminothiol (a signal from PBS served as the baseline). After 110 minutes and after rinsing by PBS buffer the incidence 
TABLE 3: Fitting parameters obtained from the proposed equivalent circuit for the different layers of the immunosensor based on SAM.

\begin{tabular}{|c|c|c|c|c|c|}
\hline Layer & $R_{s}\left(\Omega \mathrm{cm}^{2}\right)$ & $R_{m}\left(\Omega \mathrm{cm}^{2}\right)$ & $\mathrm{CPE}\left(\mathrm{Fcm}^{2}\right)$ & $\alpha_{\mathrm{CPE}}$ & $\chi^{2}$ \\
\hline Bare gold & 51.63 & 8292 & $1.8847 \mathrm{E}-5$ & 0.96414 & 0.0011 \\
\hline Thiol & 47.18 & 37120 & $4.0271 \mathrm{E}-6$ & 0.9475 & 0.00058 \\
\hline GA & 49.26 & 62535 & $3.2506 \mathrm{E}-6$ & 0.94902 & 0.0011 \\
\hline Neutv. & 43.22 & 48703 & $3.9494 \mathrm{E}-6$ & 0.93945 & 0.0010 \\
\hline $\mathrm{Ab}$ & 44.63 & 39869 & $4.1848 \mathrm{E}-6$ & 0.93169 & 0.0010 \\
\hline
\end{tabular}

TABLE 4: Fitting parameters obtained from the proposed equivalent circuit for the different layers of the immunosensor based on iron oxide nanoparticles.

\begin{tabular}{lcccc}
\hline Layer & $R_{s}\left(\Omega \mathrm{cm}^{2}\right)$ & $R_{m}\left(\Omega \mathrm{cm}^{2}\right)$ & $\mathrm{CPE}(\mathrm{Fcm})^{2}$ & $\alpha_{\mathrm{CPE}}$ \\
\hline Bare gold & 51.63 & 8292 & $1.8847 \mathrm{E}-5$ & 0.96414 \\
Thiol & 47.18 & 47280 & $4.4323 \mathrm{E}-6$ & 0.95475 \\
Iron oxide nanoparticles & 43.22 & 52673 & $3.0594 \mathrm{E}-6$ & 0.92432 \\
$\mathrm{Ab}$ & 44.63 & 74200 & $4.1848 \mathrm{E}-6$ & 0.00023 \\
\hline
\end{tabular}

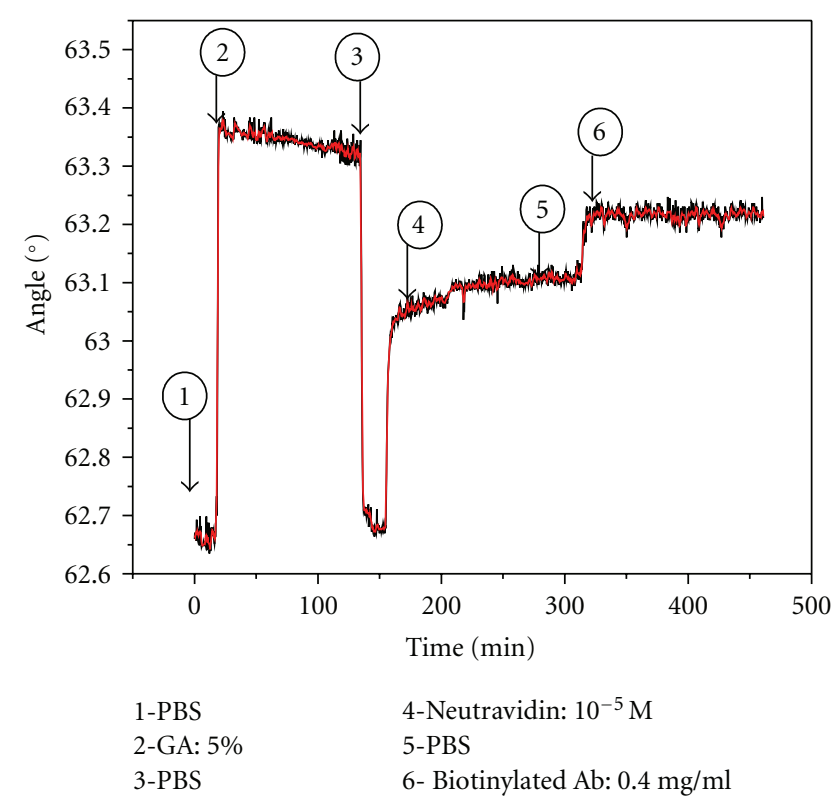

FIGURE 5: Building-up kinetics of the biofilm based on SAM. SPR responses for the step-by-step formation of multilayer. All measurements were performed in the flow cell, in PBS $10 \mathrm{mM} \mathrm{pH}$ 7.4 .

angle was increased of $0.031^{\circ}$ compared with the base line, indicating that a stable grafting of GA was achieved [29]. In the second step, neutravidin solution $\left(10^{-5} \mathrm{M}\right)$ was injected; this injection was accompanied by sharp changes in the signal until its saturation, suggesting that the neutravidin was indeed immobilized onto the GA activated surface. After 120 minutes of the injection, the SPR angle did not decrease during PBS flow, indicating that a stable immobilization of Neutravidin was achieved by covalent binding. An incidence angle shift of $0.465^{\circ}$ was observed. Finely, Biotinylated Ab $(0.4 \mathrm{mg} / \mathrm{ml})$ was injected. An increase of $0.12^{\circ}$ in incidence angle was observed after PBS flow, indicating an efficient binding reaction between biotinylated $\mathrm{Ab}$ and neutravidin

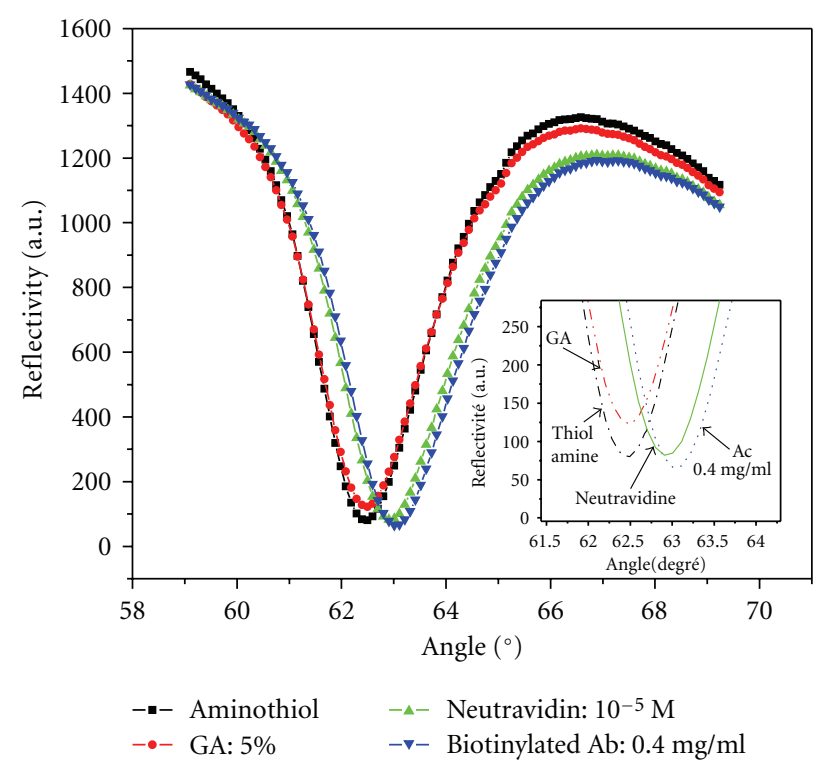

FIGURE 6: In situ SPR curves (reflected intensity $(R)$ versus incidence angle $(\theta)$ ) corresponding to the various layers grafted onto the gold electrode (system based on SAM): AUT, AUT-GA, AUTGA-Neut., and AUT-GA- Neut.- Biot.ScAb.

(immobilization by biotin/avidin affinity) [39]. Using the incidence angle shift, the covering rate of antibody was determined according to

$$
\Gamma_{\mathrm{Ab}}=\frac{(\Delta \theta / K)}{(d n / d c)},
$$

where $\Delta \theta, K$, and $d n / d c$ represent, respectively, variation of the incidence angle, conversion constant $(5300 \mathrm{~s}$ of $\mathrm{arc} / \mathrm{nm})$ and refractive index increments $\left(0.188 \mathrm{~cm}^{3} / \mathrm{g}\right.$ for the protein). For system 1, the covering rate of antibody reached $0.37 \mathrm{ng} / \mathrm{mm}^{2}$ which corresponds to a surface density of antibody immobilized on the modified gold electrode of $148 \times 10^{9} \mathrm{Ab}$ molecules $/ \mathrm{mm}^{2}$. With this surface density, the 
TABLE 5: Comparison of analytical parameters of immunosensors based on SAM and immunosensor based on iron oxide nanoparticles.

\begin{tabular}{|c|c|c|c|}
\hline & Analytical parameters & SAM system & IrNp System \\
\hline \multirow{5}{*}{ Optical characterization } & detection limit & $4.5 \mu \mathrm{g} / \mathrm{ml}$ & $300 \mathrm{ng} / \mathrm{ml}$ \\
\hline & sensitivity & $0.003^{\circ} \cdot \mu \mathrm{g}^{-1} \cdot \mathrm{ml}$ & $0.094^{\circ} \cdot \mu \mathrm{g}^{-1} \cdot \mathrm{ml}$ \\
\hline & Dynamic range & 4.5 to $15 \mu \mathrm{g} / \mathrm{ml}$ & 0.3 to $1 \mu \mathrm{g} / \mathrm{ml}$ \\
\hline & The time response & 45 minutes & 30 minutes \\
\hline & reproducibility & $6.3 \%$ & $5.7 \%$ \\
\hline \multirow{5}{*}{ Electrical characterization } & detection limit & $1 \mathrm{ng} \mathrm{ml}^{-1}$ & $500 \mathrm{pg} \mathrm{ml}^{-1}$ \\
\hline & sensitivity & $257.3 \Omega \cdot \mathrm{cm}^{2} \cdot \mu \mathrm{g}^{-1} \cdot \mathrm{ml}$ & $1871 \Omega \cdot \mathrm{cm}^{2} \cdot \mu \mathrm{g}^{-1} \cdot \mathrm{ml}$ \\
\hline & Dynamic range & 1 to $50 \mathrm{ng} \mathrm{ml}^{-1}$ & 0.5 to $50 \mathrm{ng} \mathrm{ml}^{-1}$ \\
\hline & The time response & 45 minutes & 20 minutes \\
\hline & reproducibility & $8.7 \%$ & $7.5 \%$ \\
\hline
\end{tabular}

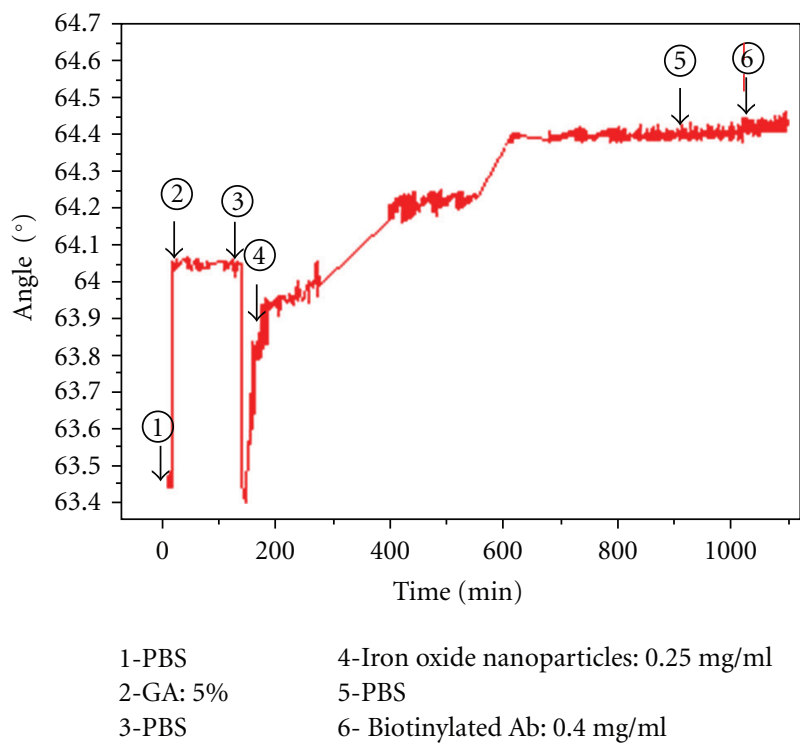

FIGURE 7: Building-up kinetics of the biofilm based on iron oxide nanoparticles. SPR responses to the step-by-step formation of multilayer. All measurements were performed in the flow cell in PBS $10 \mathrm{mM} \mathrm{pH} \mathrm{7.4.}$

average surface occupied by each Ab molecule of $6.73 \times$ $10^{-10} \mathrm{~mm}^{2}$ was obtained.

For each step of grafting of the layers constituting the immunosensor membrane, the spectra presenting the reflected intensity versus incidence angle, after flowing PBS buffer, were recorded (see Figure 6). The thickness of each layer was calculated by fitting these spectra using the Winspall program. The refractive index used to fit the data for the protein layers was $n=1.45$ [40]. This refractive index was assumed to be similar for all of the proteins and is commonly assumed for proteins studied by SPR. The fitting parameters are given in Table 1. Furthermore, this fitting allows estimating the dielectric constant $\varepsilon$. of each layer from (3).

In the same way, the building up of the membrane of immunosensor based on iron oxide nanoparticles was in situ controlled by SPR technique. Figure 7 shows the SPR angle sensorgrams. The results show that a stable immobilization

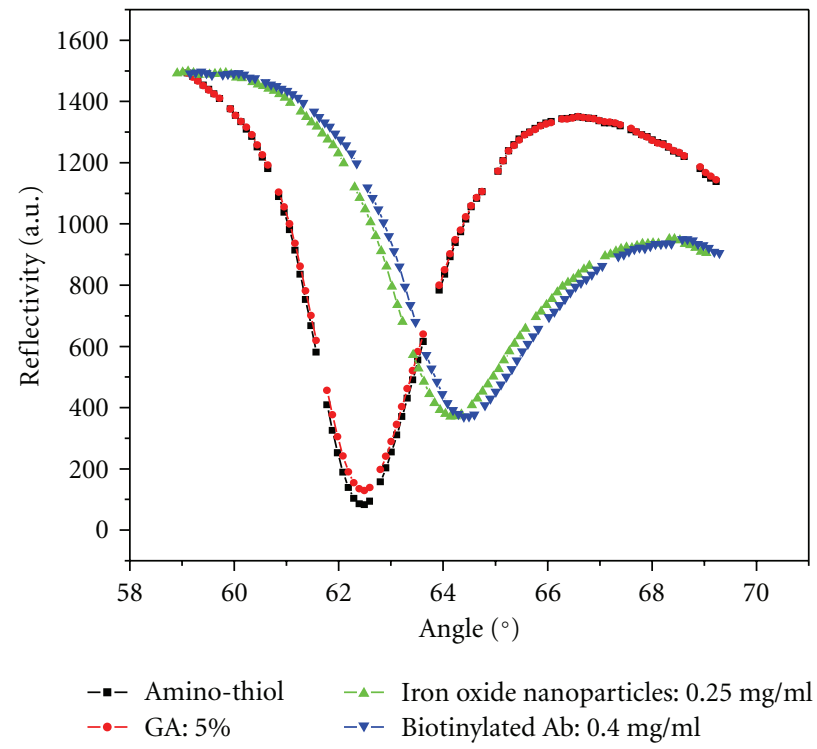

FIGURE 8: In situ SPR curves (reflected intensity $(R)$ versus incidence angle $(\theta)$ ) corresponding to the various layers grafted onto the gold electrode (system based on SAM): AUT, AUT-GA, AUT-GA-IrNP, and AUT-GA-IrNP. - Biot.ScAb.

of GA was indicated by the increase of the incidence angle of $0.031^{\circ}$ compared to the base line. The immobilization of GA was achieved by the covalent binding of the amino group of the modified gold electrode by reaction with aldehyde groups of glutaraldehyde. Afterwards, iron oxide nanoparticles solution $(0.25 \mathrm{mg} / \mathrm{ml})$ was injected on the new surface rich of aldehyde groups of glutaraldehyde. This injection was accompanied by sharp changes in the signal until its saturation, suggesting that the nanoparticles was indeed immobilized onto the GA activated surface. After 13 hours of the injection, the SPR angle did not decrease during the PBS flow, indicating that a stable immobilization of nanoparticles was achieved by covalent binding. An incidence angle shift of $1.681^{\circ}$ was observed. Finely, Biotinylated $\mathrm{Ab}(0.4 \mathrm{mg} / \mathrm{ml})$ immobilized by biotin/avidin affinity leading to an incidence angle shift of $0.266^{\circ}$.

For system 2, the covering rate of antibody reached $\Gamma_{\mathrm{Ab}}=0.95 \mathrm{mg} / \mathrm{mm}^{2}$ which corresponds to a surface density 


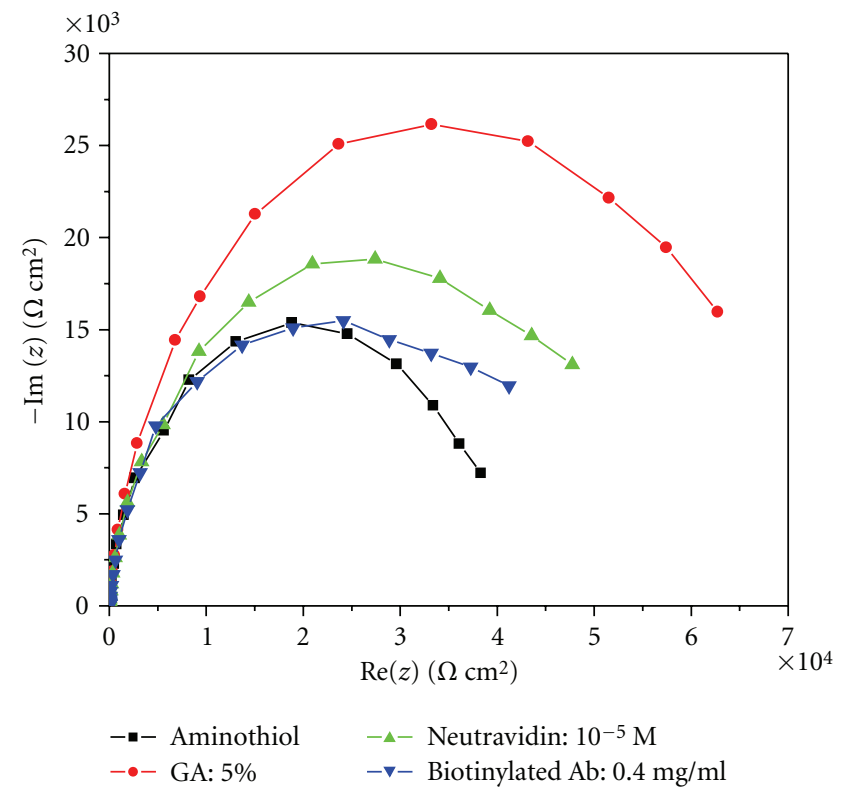

Figure 9: Nyquist diagram $(-\operatorname{Im}(z)$ versus $\operatorname{Re}(z))$ for the nonFaradic impedance measurements (at $-400 \mathrm{mV}$ versus SCE, in PBS solution $10 \mathrm{mM} \mathrm{pH} \mathrm{7.4)} \mathrm{corresponding} \mathrm{to} \mathrm{the} \mathrm{various} \mathrm{layers}$ grafted onto the gold electrode (system based on SAM): AUT, AUTGA, AUT-GA-Neut., and AUT-GA-Neut.- Biot.ScAb. Spectra were obtained between $0.05 \mathrm{~Hz}$ and $100 \mathrm{kHz}$. Amplitude of ac voltage: $10 \mathrm{mV}$.

of antibody immobilized on the modified gold electrode of $3.81 \times 10^{9} \mathrm{Ab}$ molecules $/ \mathrm{mm}^{2}$ which correspond to a doubled surface density compared to system 1 .

For each step of grafting of the layers constituting the immunosensor membrane, the spectra presenting the reflected intensity versus incidence angle, after rinsing by PBS buffer, were recorded (see Figure 8). These spectra show the incidence angle shifts which correspond to each layer of the biofilm based on the iron oxide nanoparticles these results show again the construction of the biofilm layer by layer. Furthermore, the thickness of each layer was calculated by fitting these spectra using the Winspall program. The fitting parameters are given in Table 2. These results show that the average thickness of the nanoparticles layer is about $301 \mathrm{~nm}$. Furthermore, AFM photograph of nanoparticles presented in Figure 1 shows their quasispherical shape. The distribution in size of the dried nanoparticles is the following one: the diameter range is between $160 \mathrm{~nm}$ to $500 \mathrm{~nm}$ with a mean diameter of $257 \mathrm{~nm}$, and $28 \%$ of nanoparticles have a diameter of $240 \mathrm{~nm}$. Therefore, the hydrodynamic diameter of the nanoparticles was determined using Malvern NanoZetasizer at $25^{\circ} \mathrm{C}$. Magnetic nanoparticles were diluted at $1 / 200$ in a $1 \mathrm{mM} \mathrm{NaCl}$ solution $\mathrm{pH}$. The nanoparticles present a hydrodynamic diameter of $284 \mathrm{~nm}$ with a polydispersity coefficient of 0.1 and a zeta potential of $-23.6 \mathrm{mV}$ due to their streptavidin coating.

The comparison of the results of both systems proved that the use of the iron oxide nanoparticles increases the

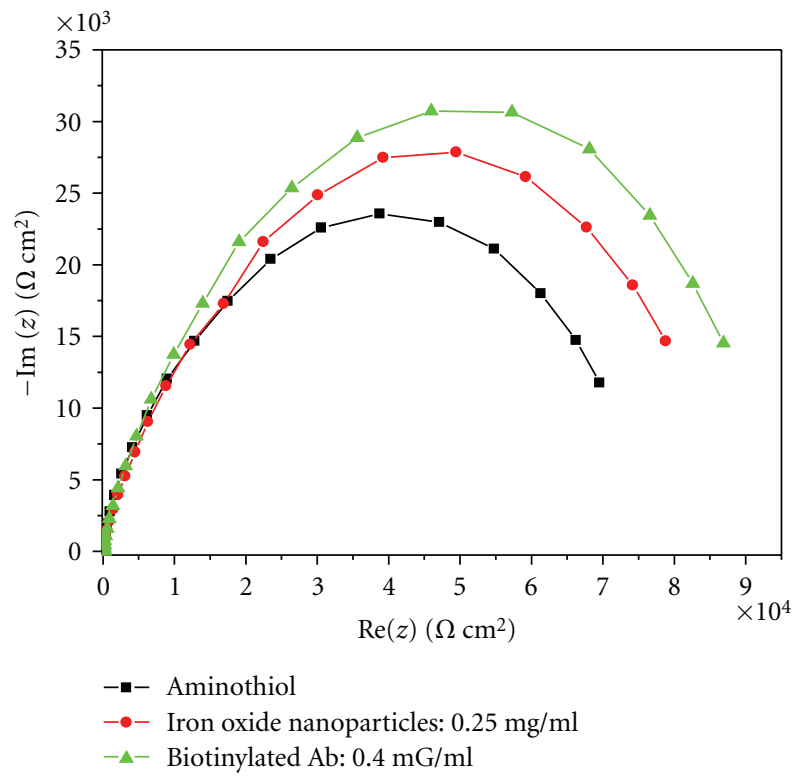

Figure 10: Nyquist diagram $(-\operatorname{Im}(z)$ versus $\operatorname{Re}(z))$ for the nonFaradic impedance measurements (at $-400 \mathrm{mV}$ versus SCE, in PBS solution $10 \mathrm{mM} \mathrm{pH} \mathrm{7.4)} \mathrm{corresponding} \mathrm{to} \mathrm{the} \mathrm{various} \mathrm{layers} \mathrm{grafted}$ onto the gold electrode (system based on iron oxide nanoparticles ): AUT, AUT-GA- IrNP., and AUT-GA-IrNP-Biot.ScAb. Spectra were obtained between $0.05 \mathrm{~Hz}$ and $100 \mathrm{kHz}$. Amplitude of ac voltage: $10 \mathrm{mV}$.

thickness of the layer of antibody from 0.4 to $1.2 \mathrm{~nm}$, from where, the increase of the grafting density of antibody on the electrode.

3.2.2. Impedance Measurement. We used EIS to control the building up of the biofilm in PBS (10 mM, pH 7) at potential $-400 \mathrm{mV}$. Figures 9 and 10 show the results of impedance spectroscopy measurements as Nyquist plots, for the assembly of the two biofilms on gold electrodes. All the electrical parameters values are presented in Table 3 and Table 4.

In the case of system 1 (based on SAM) (Figure 9), the fitting data (Table 3 ), the results show an increase of the membrane resistance $R_{m}$, of 37120 to $62535 \Omega \mathrm{cm}^{2}$, for GA film which reflected clearly the attachment of the GA film on the aminothiol functionalized electrode. Therefore, the capacitance element decreases, this is due to an increase in the thickness of the layer relating to

$$
C_{\mathrm{CPE}}=\frac{\varepsilon_{0} \varepsilon_{i} A}{d_{i}}
$$

where $\varepsilon_{0}$ is the vacuum dielectric constant $\left(8.85 \times 10^{-14}\right.$ $\left.\mathrm{F} / \mathrm{cm}^{2}\right), \varepsilon_{i}$ is the dielectric constant of the layer $i, A$ is the area of the surface, and $d_{i}$ is the thickness of the layer. Afterwards, the decrease of $R_{m}$, during the grafting of neutravidin, further indicated the subsequent attachment of neutravidin on the modified electrode. Therefore, the 


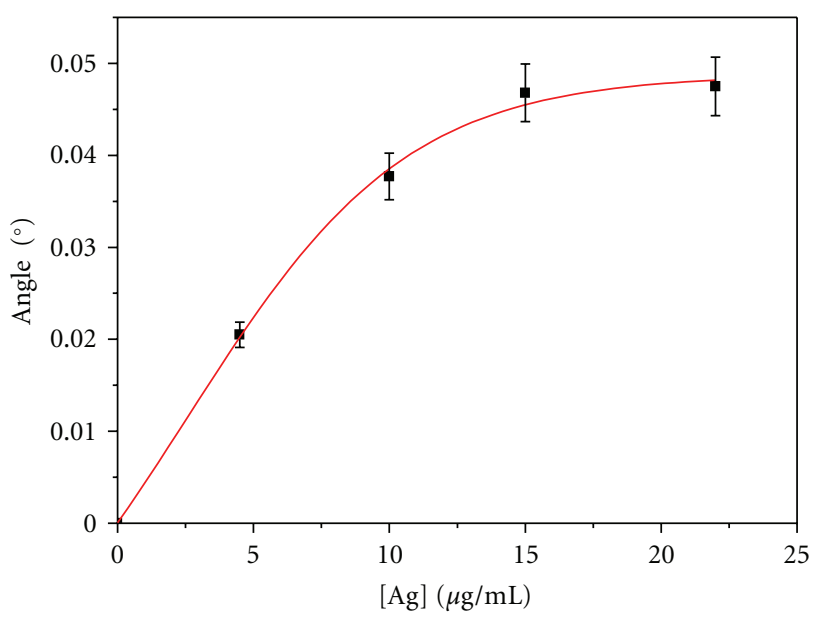

(a) Detection using system 1 based on SAM

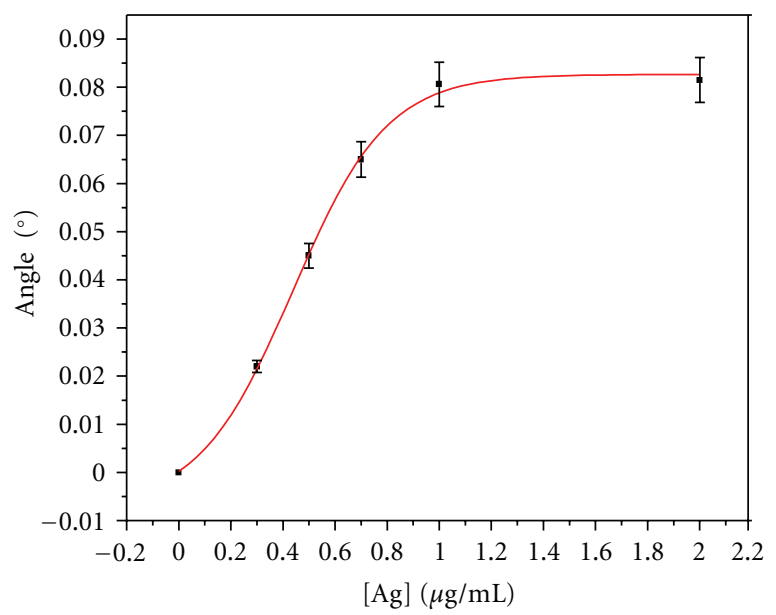

(b) Detection using system 2 based on iron oxide nanoparticles

Figure 11: Optical calibration curves describing the variation of angle shift $\Delta \theta$ against antigen concentrations:

capacitance element increases, this is due to an increase in the dielectric constant, due to an increase in the conductivity that can be due to the grafting of a charged protein (neutravidin). Finely, the subsequent immobilization of scAb on the electrode was indicated by a decrease of $R_{m}$.

In the same measuring conditions, the building up of the biofilm of immunosensor based on iron oxide nanoparticles was controlled by EIS (Figure 10). From the fitting data (Table 4), The results show an increase of the membrane resistance $R_{m}$ for IrNP film compared with SAM film, which reflected clearly the attachment of the IrNP film on modified electrode (no impedance measurements were performed when GA coupled SAM with IrNP). Therefore, the formation of an IrNP film will partially reduce the electron transfer of the modified electrode, so the conductivity of the whole IrNP layer decreases. Finally, the subsequent immobilization of $s c \mathrm{Ab}$ on the electrode was indicated by an increase of $R_{m}$.

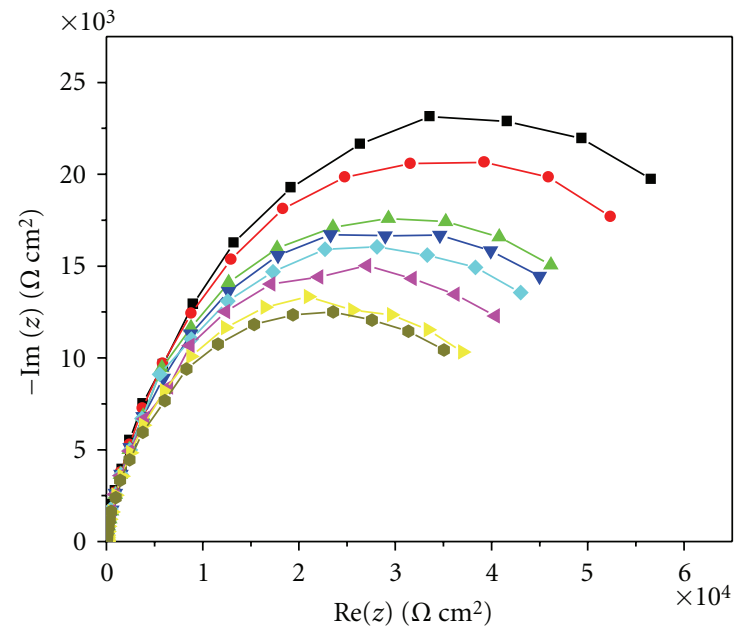

$$
\begin{array}{ll}
-- \text { Biot-Ab } 0.4 \mathrm{mg} / \mathrm{ml} & \longrightarrow \text { Ag } 500 \mathrm{ng} / \mathrm{ml} \\
-- \text { Ag } 1 \mathrm{ng} / \mathrm{ml} & -\varangle \text { Ag } 1 \mu \mathrm{g} / \mathrm{ml} \\
-\triangle-\text { Ag } 50 \mathrm{ng} / \mathrm{ml} & - \text { Ag } 4.5 \mu \mathrm{g} / \mathrm{ml} \\
-\nabla-\text { Ag } 100 \mathrm{ng} / \mathrm{ml} & - \text { Ag } 22 \mu \mathrm{g} / \mathrm{ml}
\end{array}
$$

(a) Detection using system 1 based on SAM

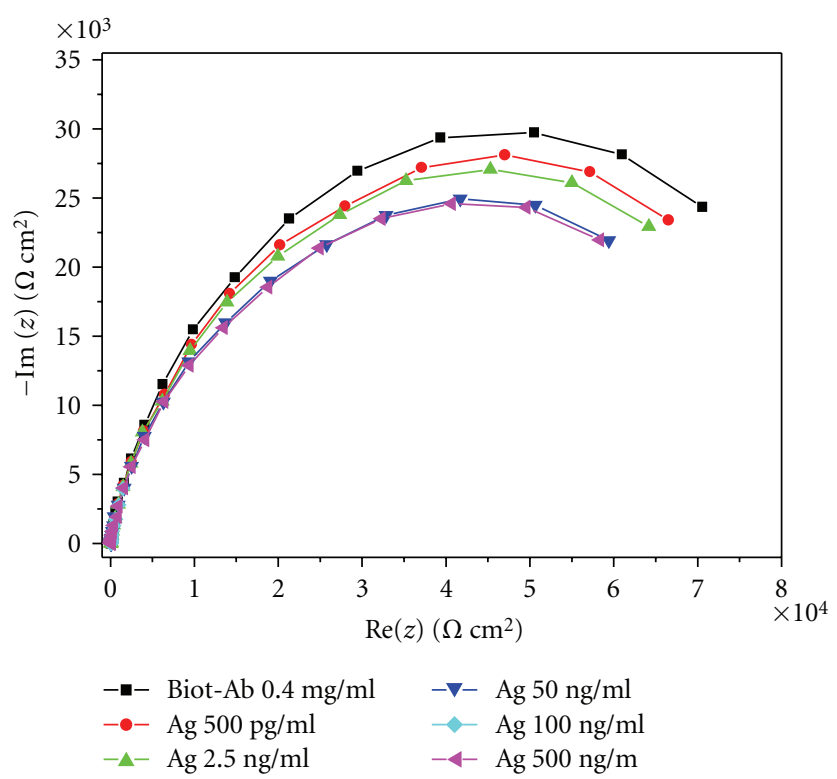

(b) Detection using system 2 based on iron oxide nanoparticles

Figure 12: Nyquist diagram $(-\operatorname{Im}(z)$ versus $\operatorname{Re}(z))$ at $-400 \mathrm{mV}$

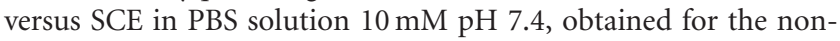
Faradic impedance measurement on modified gold electrode with biotin tagged reduced antibody under various concentrations of antigen.

\subsection{Electrical and Optical Detection via System 1 (Based on SAM) and via System 2 (Based on Iron Oxide Nanoparticles)}

3.3.1. Optical Detection. In order to study the comparison of the two immunosensors responses, the optical calibration curves corresponding to the variation of incidence angle $\Delta \theta$ versus concentrations of specific antigen in PBS solution was 
presented in Figure 11. Figure 11(a) presents the response of immunosensor developed with system 1 . The immunosensor calibration curve with $\mathrm{Ag}$ concentrations presents a saturation part; however, the immunosensor response exhibits a linear relation between $\theta$ and the Ag concentrations ranging from 4.5 to $15 \mu \mathrm{g} / \mathrm{ml}$ with a detection limit of $4.5 \mu \mathrm{g} / \mathrm{ml}$, and an average response time of 45 minutes. The linear regression equation was $\boldsymbol{\theta}=\mathbf{0 . 0 0 3}[\mathbf{A g}]+\mathbf{0 . 0 0 3}$, with a correlation coefficient of 0.96. Figure 11(b) presents the response of immunosensor developed with system 2 . The immunosensor calibration curve with Ag concentration presents a saturation part; however, the immunosensor response exhibits a linear relation between $\theta$ and the Ag concentration ranging from 0.3 to $1 \mu \mathrm{g} / \mathrm{ml}$ with a detection limit of $300 \mathrm{ng} / \mathrm{ml}$, and an average response time of 30 minutes. The linear regression equation was $\boldsymbol{\theta}=\mathbf{0 . 0 9 4}[\mathbf{A g}]+\mathbf{0 . 0 0 2}$, with a correlation coefficient of 0.98 . Consequently, the results show a higher response in the case of the immunosensor based on iron oxide nanoparticles compared to immunosensor based on SAM.

3.3.2. Electrical Detection. Antigen-Antibody interactions were monitored by impedance spectroscopy in PBS solution $(10 \mathrm{mM}, \mathrm{pH} 7)$ at $-400 \mathrm{mV}$ for system 1 and for system 2. Systematically, the electrodes modified with biotin-tagged antibody fragment were equilibrated with a range of concentrations of the specific antigen. The impedance spectra obtained after incubation with different concentrations of Antigen are shown in Figure 12. Immediately the impedance decreases clearly with the increase of $[\mathrm{Ag}]$, which indicates that a larger amount of Antigen was linked to the specific sites and the electron transfer decreases.

In order to study the comparison of both immunosensors responses, the electrical calibration curves corresponding to the variation of membrane resistance $\Delta R_{m}$ versus concentrations of specific antigen in PBS solution, was presented in Figure 13. Figure 13(a) presents the response of immunosensor developed with system 1 . The immunosensor calibration curve with Ag concentration presents a saturation part; however, the immunosensor exhibits a linear relation between $R_{m}$ and the $\mathrm{Ag}$ concentration ranging from 1 to $50 \mathrm{ng} \mathrm{ml}^{-1}$ with a detection limit of $1 \mathrm{ng} \mathrm{ml}^{-1}$, and an overage response time of 45 minutes. The linear regression equation in the range from 1 to $50 \mathrm{ng} \mathrm{ml}^{-1}$ was $R_{m}=257.3[\mathrm{Ag}] 3.248$, with a correlation coefficient of 0.83 . Figure 13 (b) presents the response of immunosensor developed with system 2 . The immunosensor calibration curve with Ag concentration presents a saturation part; however, the immunosensor exhibits a linear relation between $R_{m}$ and the Ag concentration ranging from 0.5 to $50 \mathrm{ng} \mathrm{ml}^{-1}$ with a detection limit of $500 \mathrm{pg} \mathrm{ml}^{-1}$, and an overage response time of 20 minutes. The linear regression equation in the range from 1 to $50 \mathrm{ng}$ $\mathrm{ml}^{-1}$ was $R_{m}=1871[\mathrm{Ag}]+0.908$, with a correlation coefficient of 0.91 . Consequently, comparing the characteristics of both Immunosensors, the results confirm that the using of the iron oxide nanoparticles improves immediately the characteristics of the immunosensor in terms of detection limit.

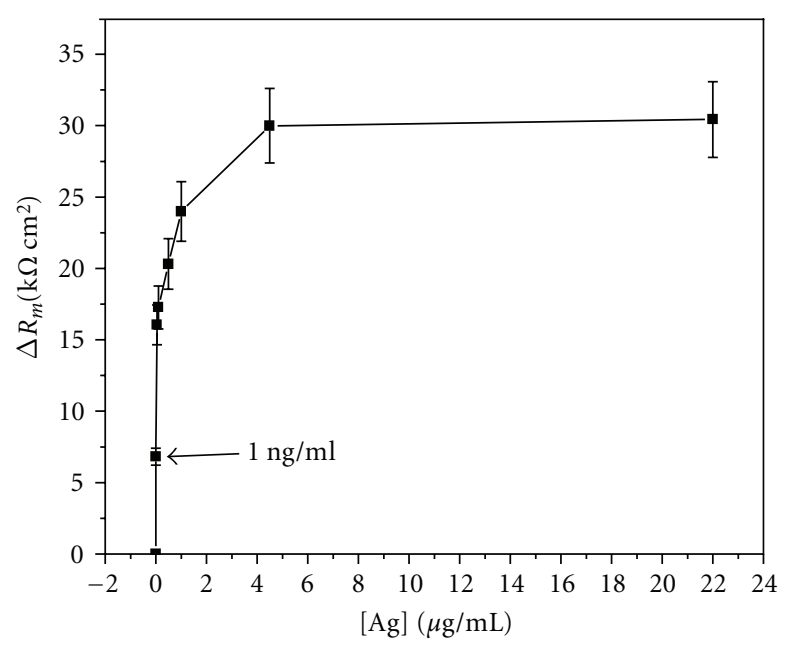

(a) Detection using system 1 based on SAM

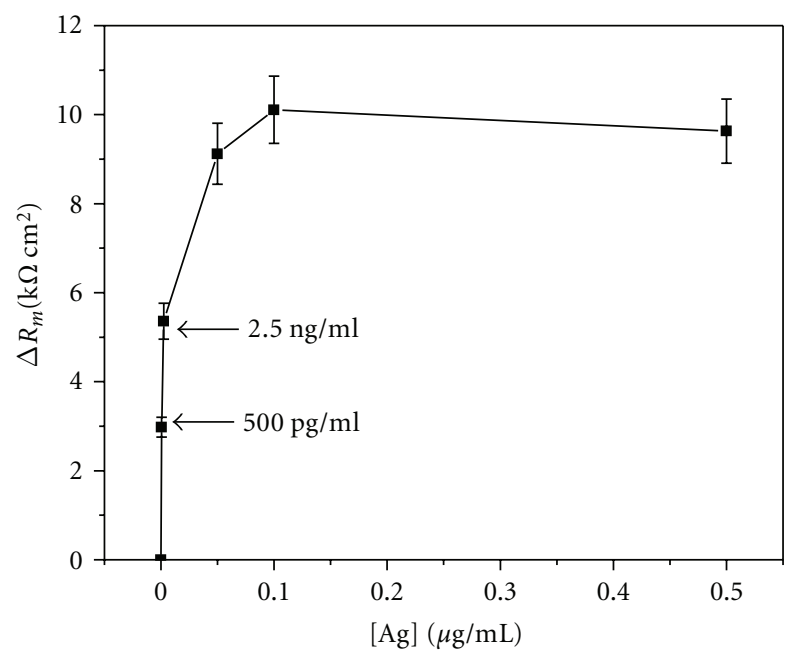

(b) Detection using system 2 based on iron oxide nanoparticles

FIGURE 13: Electrical calibration curves describing the variation of membrane resistance $\Delta \mathrm{R}_{\mathrm{m}}$ against antigen concentrations.

\section{Conclusion}

In this study, we have developed an immunosensor based on functionalized iron oxide nanoparticles. By comparison with the development of an immunosensor based on SAM, we have demonstrated that the use of the functionalized iron oxide nanoparticles offers several advantages. The comparison of the results of both systems proved that the use of the iron oxide nanoparticles amplifies the response signal, so increases the thickness of the layer of antibody from 0.4 to $1.2 \mathrm{~nm}$, from where, the increase of the grafting density of antibody on the electrode. In second time, we have demonstrated that by using electrochemical impedance spectroscopy combined with theoretical equivalent circuits models it is possible to determine the electrical properties. Furthermore, EIS allowed a thorough monitoring of the engineering of the biolayer membrane.

Table 5 shows the comparison of analytical parameters of immunosensors based on SAM and immunosensor based 
on iron oxide nanoparticles from electrical and optical characterization. The comparison of characteristics of both immunosensors has showed that nanoparticles permitted to obtain the best characteristics. So, antibody immobilization on nanoparticles permitted to reach sensitivity and to reach lower detection limit: $500 \mathrm{pg} / \mathrm{ml}$ instead of $1 \mathrm{ng} / \mathrm{ml}$ to in the case of EIS and $300 \mathrm{ng} / \mathrm{ml}$ instead of $4.5 \mu \mathrm{g} / \mathrm{ml}$ in the case of SPR. Thus, it permitted to improve the sensitivity from $257.3 \Omega \cdot \mathrm{cm}^{2} \cdot \mu \mathrm{g}^{-1} \cdot \mathrm{ml}$ to $1871 \Omega \cdot \mathrm{cm}^{2} \cdot \mu \mathrm{g}^{-1} \cdot \mathrm{ml}$ in the case of EIS and from $0.003^{\circ} \cdot \mu \mathrm{g}^{-1} \cdot \mathrm{ml}$ to $0.094^{\circ} \cdot \mu \mathrm{g}^{-1} \cdot \mathrm{ml}$ in the case of SPR.

\section{References}

[1] S. Helali, A. Abdelghani, I. Hafaiedh, et al., "Functionalization of niobium electrodes for the construction of impedimetric biosensors," Materials Science and Engineering C, vol. 28, no. 5-6, pp. 826-830, 2008.

[2] J. Ramón-Azcón, E. Valera, Á. Rodríguez, et al., "An impedimetric immunosensor based on interdigitated microelectrodes (ID $\mu \mathrm{E})$ for the determination of atrazine residues in food samples," Biosensors \& Bioelectronics, vol. 23, no. 9, pp. 1367-1373, 2008.

[3] I.-S. Park and N. Kim, "Development of a chemiluminescent immunosensor for chloramphenicol," Analytica Chimica Acta, vol. 578, no. 1, pp. 19-24, 2006.

[4] M. Hnaien, M. F. Diouani, S. Helali, et al., "Immobilization of specific antibody on SAM functionalized gold electrode for rabies virus detection by electrochemical impedance spectroscopy," Biochemical Engineering Journal, vol. 39, no. 3, pp. 443-449, 2008.

[5] I. M. Ciumasu, P. M. Krämer, C. M. Weber, et al., "A new, versatile field immunosensor for environmental pollutants: development and proof of principle with TNT, diuron, and atrazine," Biosensors \& Bioelectronics, vol. 21, no. 2, pp. 354364, 2005.

[6] B. Qu, X. Chu, G. Shen, and R. Yu, "A novel electrochemical immunosensor based on colabeled silica nanoparticles for determination of total prostate specific antigen in human serum," Talanta, vol. 76, no. 4, pp. 785-790, 2008.

[7] M. Hnaiein, W. M. Hassen, A. Abdelghani, et al., "A conductometric immunosensor based on functionalized magnetite nanoparticles for E. coli detection," Electrochemistry Communications, vol. 10, no. 8, pp. 1152-1154, 2008.

[8] Y. Y. Xu, C. Bian, Sh. Chen, and S. Xia, "A microelectronic technology based amperometric immunosensor for $\alpha$ fetoprotein using mixed self-assembled monolayers and gold nanoparticles," Analytica Chimica Acta, vol. 561, no. 1-2, pp. 48-54, 2006.

[9] A. C. Templeton, J. J. Pietron, R. W. Murray, and P. Mulvaney, "Solvent refractive index and core charge influences on the surface plasmon absorbance of alkanethiolate monolayerprotected gold clusters," Journal of Physical Chemistry B, vol. 104, no. 3, pp. 564-570, 2000.

[10] C. Demaille, M. Brust, M. Tsionsky, and A. J. Bard, "Fabrication and characterization of self-assembled spherical gold ultramicroelectrodes," Analytical Chemistry, vol. 69, no. 13, pp. 2323-2328, 1997.

[11] N. Chandrasekharan and P. V. Kamat, "Improving the photoelectrochemical performance of nanostructured $\mathrm{TiO}_{2}$ films by adsorption of gold nanoparticles," Journal of Physical Chemistry B, vol. 104, no. 46, pp. 10851-10857, 2000.
[12] G. Peto, G. L. Molnar, Z. Paszti, O. Geszti, A. Beck, and L. Guczi, "Electronic structure of gold nanoparticles deposited on $\mathrm{SiOx} / \mathrm{Si}(100)$," Materials Science and Engineering C, vol. 19, no. 1-2, pp. 95-99, 2002.

[13] N. Jaffrezic-Renault, C. Martelet, Y. Chevolot, and J.-P. Cloarec, "Biosensors and bio-bar code assays based on biofunctionalized magnetic microbeads," Sensors, vol. 7, no. 4, pp. 589-614, 2007.

[14] W. M. Hassen, L. Angnes, A. Abdelghani, F. Bessueille, D. Leonard, and N. Jaffrezic-Renault, "Under flow impedimetric measurements using magnetic particles for label-free detection affinity target," Materials Science and Engineering $C$, vol. 28, no. 5-6, pp. 820-825, 2008.

[15] W. M. Hassen, C. Chaix, A. Abdelghani, F. Bessueille, D. Leonard, and N. Jaffrezic-Renault, "An impedimetric DNA sensor based on functionalized magnetic nanoparticles for HIV and HBV detection," Sensors and Actuators B, vol. 134, no. 2, pp. 755-760, 2008.

[16] Q. A. Pankhurst, J. Connolly, S. K. Jones, and J. Dobson, "Applications of magnetic nanoparticles in biomedicine," Journal of Physics D, vol. 36, pp. R167-R181, 2003.

[17] M. A. M. Gijs, "Magnetic bead handling on-chip: new opportunities for analytical applications," Microfluidics and Nanofluidics, vol. 1, no. 1, pp. 22-40, 2004.

[18] M. Shinkai, "Functional magnetic particles for medical application," Journal of Bioscience and Bioengineering, vol. 94, no. 6, pp. 606-613, 2002.

[19] C. Berggren and G. Johansson, "Capacitance measurements of antibody-sntigen interactions in a flow system," Analytical Chemistry, vol. 69, no. 18, pp. 3651-3657, 1997.

[20] A. C. Howard, H. Z. Daniel, and O. Marc, "In vivo $\mathrm{CH}_{3}\left(\mathrm{CH}_{2}\right)_{11} \mathrm{SAu}$ SAM electrodes in the beating heart: in situ analytical studies relevant to pacemakers and interstitial biosensors," Biosensors \& Bioelectronics, vol. 18, no. 1, pp. 1121, 2003.

[21] M. M. Vladimir, "New electroanalytical applications of selfassembled monolayers," Trends in Analytical Chemistry, vol. 21, no. 6-7, pp. 439-450, 2002.

[22] S. Hleli, C. Martelet, A. Abdelghani, N. Burais, and N. Jaffrezic-Renault, "Atrazine analysis using an impedimetric immunosensor based on mixed biotinylated self-assembled monolayer," Sensors and Actuators B, vol. 113, no. 2, pp. 711717, 2006.

[23] M. M. Vladimir, R. Michael, and S. W. Otto, "Capacitive monitoring of protein immobilization and antigen-antibody reactions on monomolecular alkylthiol films on gold electrodes," Biosensors \& Bioelectronics, vol. 12, no. 9-10, pp. 977989, 1997.

[24] J. Melendez, R. Carr, D. U. Bartholomew, et al., "A commercial solution for surface plasmon sensing," Sensors and Actuators B, vol. 35, no. 1-3, pp. 212-216, 1996.

[25] L. S. Jung, J. S. Shumaker-Parry, C. T. Campbell, S. S. Yee, and M. H. Gelb, "Quantification of tight binding to surfaceimmobilized phospholipid vesicles using surface plasmon resonance: binding constant of phospholipase $\mathrm{A}_{2}$," Journal of the American Chemical Society, vol. 122, no. 17, pp. 4177-4184, 2000.

[26] W.-C. Law, P. Markowicz, K.-T. Yong, et al., "Wide dynamic range phase-sensitive surface plasmon resonance biosensor based on measuring the modulation harmonics," Biosensors \& Bioelectronics, vol. 23, no. 5, pp. 627-632, 2007.

[27] A. Hallik, A. Alumaa, J. Tamm, et al., "Analysis of electrochemical impedance of polypyrrole," Synthetic Metals, vol. 156, no. 5-6, pp. 488-494, 2006. 
[28] C. Ehrenbeck, K. Jüttner, S. Ludwig, and G. Paasch, "The electrochemical impedance of a free-standing polypyrrole membrane," Electrochimica Acta, vol. 43, no. 19-20, pp. 27812789, 1998.

[29] D. D. MacDonald, "Reflections on the history of electrochemical impedance spectroscopy," Electrochimica Acta, vol. 51, no. 8-9, pp. 1376-1388, 2006.

[30] M. Wang, L. Wang, G. Wang, et al., "Application of impedance spectroscopy for monitoring colloid Au-enhanced antibody immobilization and antibody-antigen reactions," Biosensors \& Bioelectronics, vol. 19, no. 6, pp. 575-582, 2004.

[31] R. Pei, Z. Cheng, E. Wang, and X. Yang, "Amplification of antigen-antibody interactions based on biotin labeled proteinstreptavidin network complex using impedance spectroscopy," Biosensors \& Bioelectronics, vol. 16, no. 6, pp. 355-361, 2001.

[32] R. K. Shervedani and S. A. Mozaffari, "Preparation and electrochemical characterization of a new nanosensor based on self-assembled monolayer of cysteamine functionalized with phosphate groups," Surface \& Coatings Technology, vol. 198, no. 1-3, pp. 123-128, 2005.

[33] X. Cui, D. Jiang, P. Diao, J. Li, R. Tong, and X. Wang, "Assessing the apparent effective thickness of alkanethiol self-assembled monolayers in different concentrations of $(\mathrm{CN})_{6} / \mathrm{Fe}(\mathrm{CN})_{6}$ by ac impedance spectroscopy," Journal of Electroanalytical Chemistry, vol. 470, no. 1, pp. 9-13, 1999.

[34] I. Navratilova and P. Skladal, "The immunosensors for measurement of 2,4-dichlorophenoxyacetic acid based on electrochemical impedance spectroscopy," Bioelectrochemistry, vol. 62, no. 1, pp. 11-18, 2004.

[35] V. Freger and S. Bason, "Characterization of ion transport in thin films using electrochemical impedance spectroscopy. I. Principles and theory," Journal of Membrane Science, vol. 302, no. 1-2, pp. 1-9, 2007.

[36] J. R. de Sousa, M. M. V. Parente, I. C. N. Diogenes, et al., "A correlation study between the conformation of the 1,4-dithiane SAM on gold and its performance to assess the heterogeneous electron-transfer reactions," Journal of Electroanalytical Chemistry, vol. 566, no. 2, pp. 443-449, 2004.

[37] A. Ramanavièius, F. W. Herberg, S. Hutschenreiter, et al., "Biomedical application of surface plasmon resonance biosensors (review)," Acta Medica Lituanica, vol. 12, p. 1, 2005.

[38] H. Raether, Surface Plasmons, Springer, New York, NY, USA, 1988.

[39] J. Wong, A. Chilkoti, and V. T. Moy, "Direct force measurements of the streptavidin-biotin interaction," Biomolecular Engineering, vol. 16, no. 1-4, pp. 45-55, 1999.

[40] W. Knoll, M. Liley, D. Piscevic, J. Spinke, and M. J. Tarlov, "Supramolecular architectures for the functionalization of solid surfaces," Advances in Biophysics, vol. 34, pp. 231-251, 1997. 

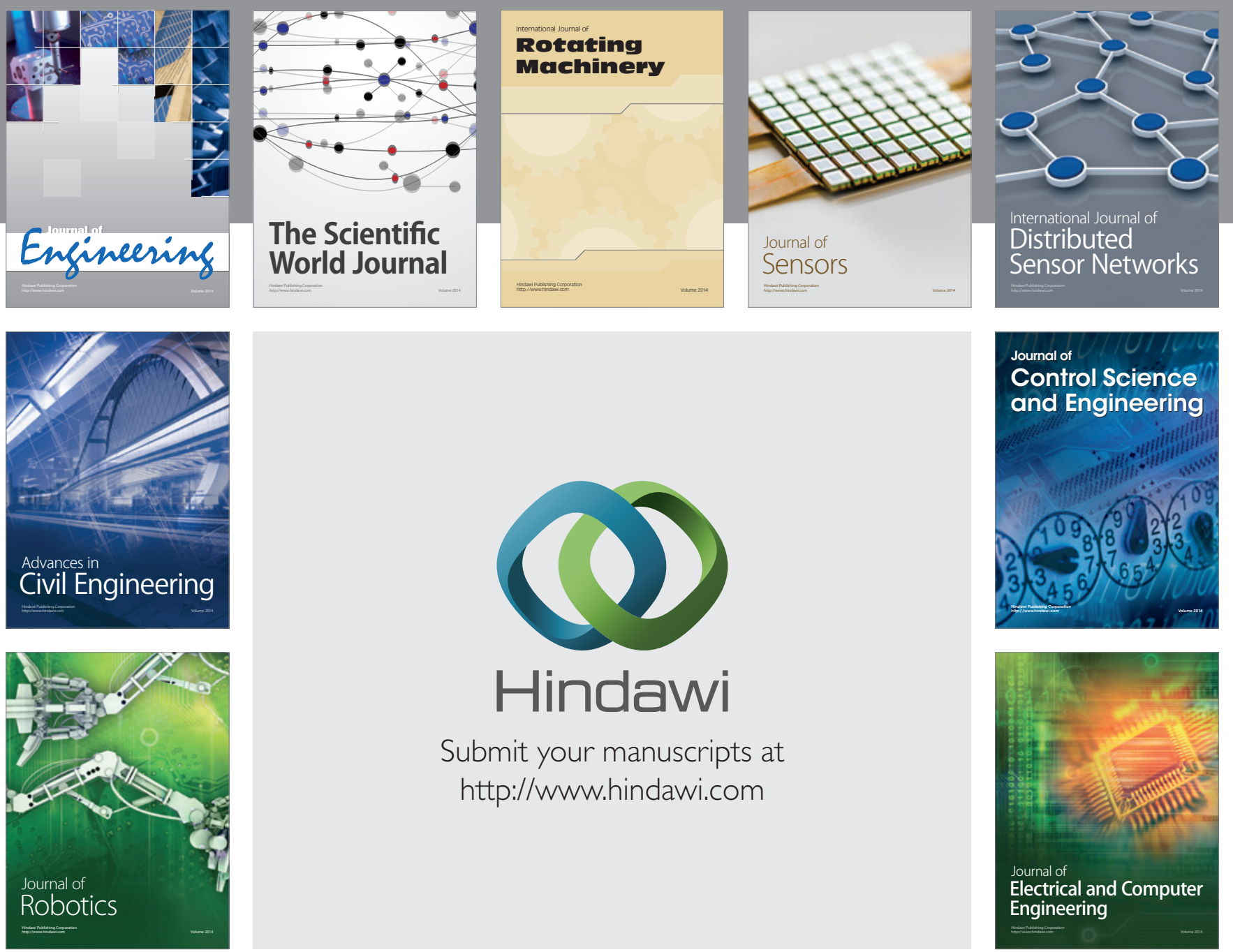

Submit your manuscripts at

http://www.hindawi.com
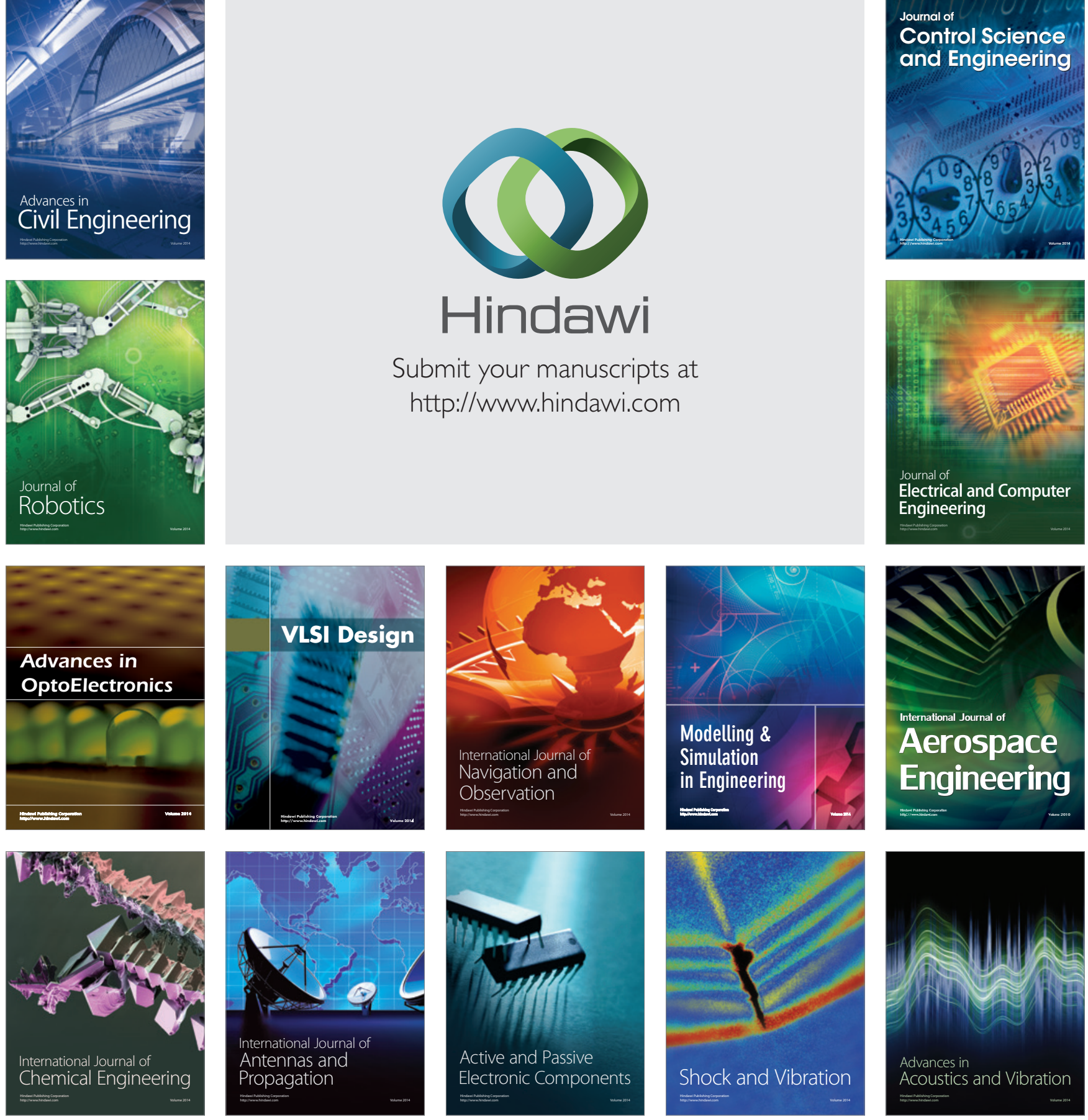